DOI: $10.5216 /$ cab.v14i3.17147

\title{
IDENTIFICAÇÃO DE MAMÍFEROS SILVESTRES DO PANTANAL SUL-MATO-GROSSENSE PORTADORES DE Leptospira spp.
}

\author{
Anahi Souto Vieira ${ }^{1}$, Grácia Maria Soares Rosinha ${ }^{2}$, Silvio Arruda Vasconcellos ${ }^{3}$, \\ Zenaide Maria de Moaris ${ }^{4}$, Rosielle Campozano Viana ${ }^{5}$, CARINa Elisei De Oliveira ${ }^{2}$, Cleber

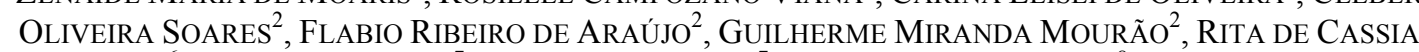 \\ BIANCHI $^{6}$, NATALIE Olifiers ${ }^{7}$, Vitor RADEMAKER ${ }^{7}$, FABIANA LOPES ROCHA ${ }^{8}$, AIESCA OlIVEIRA \\ PELLEGRIN $^{9}$
}

\footnotetext{
1Médica Veterinária, Mestre, Universidade Federal de Mato Grosso do Sul, Campo Garnde, MS, Brasil. anahi_sv@yahoo.com.br 2Pesquisadores Doutores da Embrapa Gado de Corte, Campo Grande, MS, Brasil. 3 Professor Colaborador Senior da Universidade de São Paulo, São Paulo, SP, Brasil 4 Técnica de nível superior da Universidade de São Paulo, São Paulo, SP, Brasil 5Bolsista PIBIc da Embrapa Pantanal, Corumbá, MS, Brasil 6Pós-Graduanda da Universidade Federal de Mato Grosso do Sul, Campo Garnde, MS, Brasil. 7Pesquisador doutor do Laboratório de Biologia e Parasitologia de Mamíferos Silvestres Reservatórios, Fundação Oswaldo Cruz, Manguinhos, RJ, Brasil.

8Pós-graduanda da Fundação Oswaldo Cruz, Manguinhos, RJ, Brasil. 9Pesquisadora Doutora da Embrapa Pantanal, Corumbá, MS, Brasil
}

Foi realizado um levantamento da infecção por Leptospira spp. em mamíferos silvestres do Pantanal sul-matogrossense com o emprego da reação de soroaglutinação microscópica (SAM) e da reação em cadeia da polimerase (PCR). Os sorovares de maior frequência nos animais investigados foram Hardjobovis (28\%), Icterohemorhagiae (12\%), M-110/2006 (isolado de Cerdocyon thous; 16\%), Canicola (L014 isolada de Bos taurus, 4\%), Whitcombi (4\%), Pomona (20\%), Autumnalis (12\%) e Copenhageni (M9/99 isolada de Rattus norvegicus, 4\%). Das 79 amostras examinadas pela PCR, 21 (26,58\%) foram positivas, com a amplificação de um fragmento de aproximadamente $331 \mathrm{pb}$. Dois fragmentos amplificados obtidos de amostras de C. thous foram clonados, sequenciados e identificados como $L$. interrogans por análise filogenética.

PALAVRAS-CHAVE: leptospirose; mamíferos silvestres; Pantanal; PCR; sorologia,

\section{IDENTIFICATION OF WILD MAMMALS FROM PANTANAL SUL- MATOGROSSENSE CARRIERS OF Leptospira spp.}

\section{ABSTRACT}

A survey of Leptospira spp. in wild mammals from the southern Pantanal of Mato Grosso do Sul was performed by microscopic agglutination test (MAT) and polymerase chain reaction (PCR). The serovars most frequently found were Hardjobovis (28\%), Icterohemorhagiae (12\%), M110/2006 strain (isolated from Cerdocyon thous, 16\%), Canicola (L014 isolated from Bos Taurus, 4\%),
Whitcombi (4\%), Pomona (20\%), Autumnalis (12\%) and Copenhageni (M9/99 isolated from Rattus norvegicus, 4\%). From the 79 samples tested by PCR, 21 (26.58\%) were positive, resulting in the amplification fragment of approximately $331 \mathrm{pb}$. Two amplified fragments from $C$. thous were cloned, sequenced and identified as $L$. interrogans by phylogenetic analysis.

KEYWORDS: leptospirosis; Pantanal; PCR; serology; wild mammals. 


\section{INTRODUÇÃO}

A leptospirose

Leptospira) é uma doença re-emergente mundialmente distribuída que afeta animais silvestres, domésticos e o ser humano (SCARCELLI et al., 2003). A doença acarreta elevados prejuízos econômicos para a pecuária do Brasil, causando abortamentos, natimortalidade, mastite, agalaxia e nascimento de bezerros fracos (BARR \& ANDERSON, 1994). Um dos maiores desafios do estudo da leptospirose tem sido a caracterização de ambientes e modos de transmissão, condições altamente dependentes dos sorovares. Alguns sorovares são endêmicos de regiões particulares e cada um deles tende a ser mantido por um hospedeiro específico. Embora as pesquisas sobre a leptospirose em animais silvestres já tenham avançado em vários países, no Brasil as informações sobre o tema ainda são escassas, deixando uma lacuna no conhecimento da cadeia epidemiológica da doença e dificultando a elaboração de planos de controle em regiões com grande densidade de animais silvestres e ambientes ecologicamente favoráveis (GIRIO et al., 2003).

$\mathrm{Na}$ região do Pantanal, as condições ecológicas são altamente favoráveis à ocorrência de leptospirose, uma vez que o microrganismo sobrevive mais tempo em áreas alagadas e com temperaturas elevadas (LINZ et al., 1986), condição comum neste bioma, que apresenta áreas extensas de várzea e campos inundáveis.

O teste considerado como "Padrão Ouro" pela Organização Mundial da Saúde para o diagnóstico da leptospirose é a soroaglutinação microscópica (SAM/ OIE, 2006). Porém, essa técnica pode apresentar reação cruzada entre sorovares. A reação em cadeia da polimerase (PCR) é um método de detecção direto, rápido, sensível e específico, que pode ser utilizado diretamente em amostras clínicas como sangue, urina ou humor aquoso (MÉRIEN et al., 1992; BALL et al., 1994). A PCR tem sido utilizada para a detecção da infecção no ser humano e nos animais domésticos, porém ainda foi pouco empregada em estudos com animais selvagens.

Os objetivos deste trabalho foram: identificar espécies de mamíferos selvagens infectados por Leptospira spp. na região do Pantanal do Estado de Mato Grosso do Sul, Brasil, utilizando as técnicas de SAM e PCR; comparar o desempenho dessas duas metodologias e caracterizar os sorovares predominantes que circulam nas populações de animais silvestres estudados.

\section{MATERIAL E MÉTODOS}

As áreas estudadas estão localizadas na região central do Pantanal brasileiro, conhecido como Pantanal da Nhecolândia $\left(18^{\circ} 59^{\prime} 115^{\prime}\right.$ ' S, $56^{\circ} 37^{\prime} 63^{\prime}$ 'N). O clima é tipicamente pantaneiro, com temperaturas elevadas $\left(19\right.$ a $\left.28^{\circ} \mathrm{C}\right)$ e médias pluviométricas de $1200 \mathrm{~mm} / \mathrm{ano}$ (GARCIA \& CASTRO, 1986).

Foram capturados 159 animais assim distribuídos: 57 roedores silvestres (49 Thrichomys pachyurus e oito Oecomys mamorae), 38 cachorros-do-mato (Cerdocyon thous), nove jaguatiricas (Leopardus pardalis) e 55 quatis (Nasua nasua). Para a captura dos roedores, foram utilizadas armadilhas do tipo Sherman e Tomahawk, para os carnívoros utilizaram-se armadilhas de ferro galvanizado tipo box trap. Os animais foram anestesiados com Zoletil $50^{\circledR}$ (Virbac) para coleta de sangue por punção cardíaca nos roedores e por punção venosa (cefálica ou safena) nos carnívoros. O sangue coletado foi acondicionado em tubos com anticoagulante (EDTA) e sem anticoagulante, para obtenção de papa de hemácias e soro, respectivamente.

A manipulação dos animais silvestres seguiu as recomendações de GANNON \& SIKES (2007), para o uso de animais silvestres em pesquisas e as capturas foram realizadas com autorização de coleta do Instituto Brasileiro do Meio Ambiente e de Recursos Naturais Renováveis (IBAMA): (16010-1) 6425591/33454426, $\quad(003 / 2006)$ $0214.000540 / 2005-82$, $(005 / 2007)$ $02014.000382 / 2007-22$, 02014.000419/07-97, 0214.000540/2005-82.

$(003 / 2006)$

A pesquisa de anticorpos aglutinantes antileptospiras foi efetuada pela reação de SAM, de acordo com GALTON et al (1965) e COLE et al (1973), os soros foram triados na diluição de 1:100 e, quando houve aglutinação, os soros foram titulados em uma série geométrica de diluição em razão dois. O título foi dado como a recíproca da 
maior diluição em que houve aglutinação (FÁ VERO et al., 2002). Para o diagnóstico, foi utilizada uma coleção de antígenos vivos, representantes de 19 sorogrupos de Leptospira interrogans, composta pelos sorovares: Icterohaemorrhagiae, Copenhageni, Canicola, Autumnalis, Pomona, Grippotyphosa, Hebdomadis, Wolffi, Bratislava, Harjobovis e Hardjoprajtino, Castellonis, Batavie, Whitcombi, Cynopteri, Butembo, Javanica, Panamá, Pyrogenes, Shermani, Tarassovi, Patoc e Sentot. Além das estirpes de referência, também foram utilizados como antígenos estirpes de leptospiras autóctones isoladas de animais domésticos e silvestres no Brasil: 4-B (VPS) isolada de gambá (Batávia ou Brasiliensis), M7-87 isolada de suíno (Pomona), M4/98 isolada de búfalo (Sejroe ou Guaricura), M9/99 isolada de rato (Icterohaemorragiae ou Copenhageni), L0-1 isolada de cão doméstico (Canicola), L0-4 isolada de suíno (Pomona), L0-14 isolada de bovino (Canicola), 2 A CAP isolada de capivara (Gripptyphosa ou Bananal), M 110/2006 isolada de cachorro-do-mato (ainda não caracterizada).

A extração do DNA genômico foi realizada utilizando-se $175 \mu 1$ de papa de hemácia, de acordo com o protocolo descrito por ARAUJO et al. (2009). Após a extração do pellet de DNA, o mesmo foi seco à temperatura ambiente $\mathrm{e}$ ressuspendido em $50 \mathrm{ml}$ de Tris EDTA $(10 \mathrm{mM}$ Tris $\mathrm{HCl} \mathrm{pH} \mathrm{7,4,1mM} \mathrm{EDTA} \mathrm{pH} \mathrm{8.0)} \mathrm{e} \mathrm{estocado} \mathrm{a}$ $-20^{\circ} \mathrm{C}$. O controle positivo foi obtido de uma cultura em meio semi-sólido (Fletcher ${ }^{\circledR)}$ de $L$. interrogans, sorovar Hardjo (Hardjoprajitno).

O par de oligonucleotídeos utilizado foi desenhado segundo MÉRIEN et al. (1992), com a amplificação de um produto de aproximadamente 331 pares de bases, que corresponde a uma região conservada do gene $16 \mathrm{~S}$ da estrutura primária de Leptospira spp. A reação de PCR seguiu o protocolo de VIEIRA et al. (2011). Os produtos da amplificação foram resolvidos por eletroforese a $100 \mathrm{~V}$ por 1 hora, separados em gel de agarose a $1 \%$, corados com Syber Gold (Ivitrogen ${ }^{\circledR}$ ) e visualizados por meio do sistema de captura de imagem X-ILP (Loccus ${ }^{\circledR}$ ) com transluminador sob luz ultravioleta.

Os produtos da PCR foram clonados em plasmídios pGEM-T Easy (Promega ${ }^{\circledR}$ ), de acordo com as instruções do fabricante, utilizando-se $E$. coli TOP10 F' como células quimicamente competentes. A purificação dos plasmídios recombinantes foi realizada com Kit de purificação
"Wizard miniprep" (Promega $\left.{ }^{\circledR}\right)$ O O sequenciamento dessas amostras foi realizado pelo método de Sanger, em sequenciador automático ABI 3100 de 16 capilares (Applied Biosystems), seguindo as recomendações do fabricante. As amostras foram sequenciadas com os oligonucleotídeos do gene $16 \mathrm{~S}$ de L. interrogans e com o oligonucleotídeos do vetor pGEM-T Easy. Posteriormente, as amostras foram analisadas por meio do Blast $\mathrm{N}$ (http://blast.ncbi.nlm.nih.gov) e alinhadas com o auxílio do programa Mega 4 (TAMURA et al., 2007).

Uma árvore filogenética para Leptospira spp. foi construída pelo método de "NeighbourJoining" (SAITO \& NEI, 1987), versão simplificada do método de mínima evolução (ME), o qual escolhe uma topologia mostrando o menor valor da soma de todos os ramos como uma estimativa correta da árvore. Para a construção da árvore filogenética, foram utilizadas as seguintes sequências: AY714984.1, FJ154579, AM050569, FJ154600，FJ154595， FJ154593， FJ154580.1, EU159692, FJ 154543.1, FJ154557.1, DQ991469.1, $\quad$ AM050586.1, $\quad$ FJ154580.1, AY293856.1, DQ991472.1, AY996790.2, AM050570, AY996796.1, FJ154549.1, FJ154549.1， FJ154544.1， FJ154552.1, EUA497661， DQ991478.1， AY631895.1， FJ 154572.1, FJ154582.1, AY631883, que estão disponíveis no banco de dados GenBank (http://www.ncbi.nlm.nih.gov).

Os resultados dos testes de SAM e PCR para C. thous e $N$. nasua foram comparados utilizando-se o teste do Qui-quadrado $\left(\chi^{2}\right)$ com, correção de Yates quando necessário e Odds Ratio (AYRES et al., 2005).

\section{RESULTADOS}

A frequência de animais sorologicamente positivos para a Leptospira spp foi de 23,28\% (Tabela 1). O número de reagentes por espécie animal e as reações avaliadas com as de variantes sorológicas mais prováveis estão demonstradas na Tabela 2.

Dos 75 animais examinados pelo PCR para Leptospira spp., $\quad 28,00 \%$ apresentaram um fragmento de aproximadamente $331 \mathrm{pb}$. A sequência de oligonucleotídeos utilizada amplificou todos os sorovares empregados na coleção utilizada para a realização da SAM. Duas amostras de papa de hemácias, números 21 e 39, colhidas de $C$. thous e positivas para Leptospira spp pela técnica de PCR, 
foram clonadas e sequenciadas. Os resultados indicaram que o DNA encontrado no animal de número 21 teve $99 \%$ de identidade e e-value $10^{-121}$ com $L$. interrogans sorovar Copenhageni (número de acesso no GenBank FJ154569.1). O segundo
DNA, do animal de número 39 , teve $97 \%$ de identidade e e-value $10^{-69} \mathrm{com} L$. interrogans sorovar Sejroe (número de acesso no GenBank FJ154558.1).

Tabela 1. Mamíferos silvestres capturados no Pantanal de Mato Grosso do Sul, Brasil, submetidos a exames laboratoriais para leptospirose segundo a espécie animal, o tipo de exame efetuado e a natureza do resultado obtido

\begin{tabular}{lcccc}
\hline Animais & $\begin{array}{c}\text { Reagentes a SAM / } \\
\text { número total }\end{array}$ & $\begin{array}{c}\text { \% Reagentes } \\
\text { SAM }\end{array}$ & $\begin{array}{c}\text { Positivos na PCR / } \\
\text { número total }\end{array}$ & $\begin{array}{c}\text { \%Reagentes } \\
\text { PCR }\end{array}$ \\
\hline T. pachyurus & $5 / 49$ & 10,20 & $2 / 13$ & 15,38 \\
O. mamorae & $0 / 8$ & 0,00 & 0 & 0,00 \\
C. thous & $13 / 38$ & 34,21 & $10 / 26$ & 38,46 \\
N. nasua & $15 / 45$ & 34,09 & $9 / 32$ & 28,12 \\
L. pardalis & $1 / 6$ & 14,28 & $0 / 4$ & 0,00 \\
Total & $34 / 146$ & 23,28 & $21 / 75$ & 28,00 \\
\hline
\end{tabular}

Tabela 2. Numero de animais reagentes e reações avaliadas no teste de SAM por espécie amostrada e o percentual de variantes sorológicas mais prováveis no teste SAM

\begin{tabular}{|c|c|c|c|c|c|c|}
\hline \multicolumn{7}{|l|}{ Espécie } \\
\hline & C. thous & T. pachyurus & L. pardalis & O. mamorae & N. nasua & Total \\
\hline $\mathrm{N}$ de reagntes & 13 & 5 & 1 & 0 & 15 & 34 \\
\hline $\mathrm{N}$ reações avaliadas & 10 & 1 & 1 & 0 & 13 & 25 \\
\hline \multicolumn{7}{|c|}{ Sorovares mais prováveis $(\%)^{* *}$} \\
\hline Hardjo (Hardjobovis) & 50 & NR & NR & NR & 15,37 & \\
\hline Icterohaemorrhagiae & NR & 100 & 100 & NR & 7,7 & \\
\hline Grippotyphosa & NR & NR & NR & NR & $\mathrm{Nr}$ & \\
\hline M 110/2006 & 10 & NR & NR & NR & 23,07 & \\
\hline Lo14 & 10 & NR & NR & NR & NR & \\
\hline Whitcombi & 10 & NR & NR & NR & NR & \\
\hline Pomona & 10 & NR & NR & NR & 38,46 & \\
\hline Autumnalis & 10 & NR & NR & NR & 7,7 & \\
\hline Australis & NR & NR & NR & NR & NR & \\
\hline Bratislava & NR & NR & NR & NR & NR & \\
\hline Cynopteri & NR & NR & NR & NR & NR & \\
\hline Copenhageni & NR & NR & NR & NR & NR & \\
\hline M9/99 & NR & NR & NR & NR & 7,7 & \\
\hline GR6 & NR & NR & NR & NR & NR & \\
\hline L04 & NR & NR & NR & NR & NR & \\
\hline Castellonis & NR & NR & NR & NR & NR & \\
\hline Pyrogenes & NR & NR & NR & NR & NR & \\
\hline L01 & NR & NR & NR & NR & NR & \\
\hline $5 \mathrm{M} 7 / 87$ & NR & NR & NR & NR & NR & \\
\hline 2 ACAP & NR & NR & NR & NR & NR & \\
\hline Tarassovi & NR & NR & NR & NR & NR & \\
\hline Hardjo (Hardjprettitno) & NR & NR & NR & NR & NR & \\
\hline Wollfi & NR & NR & NR & NR & NR & \\
\hline
\end{tabular}

* número de reações aproveitadas, sendo desconsideradas aquelas com título mais alto idêntico para dois ou mais sorovares.

** percentual de reações por sorovar, considerando apenas os reagentes mais prováveis.

NR: não reagente. 
Com a construção da árvore filogenética, observou-se a separação de Leptospira biflexa patoc, Tuneria parva Parva e Leptonema ilinni Illini - out group, (MOREY et al., 2006 ), de um grande grupo formado por leptospiras patogênicas. Os isolados de C. thous foram similares à $L$. 3,$33 ; \mathrm{p}=1,45)$.

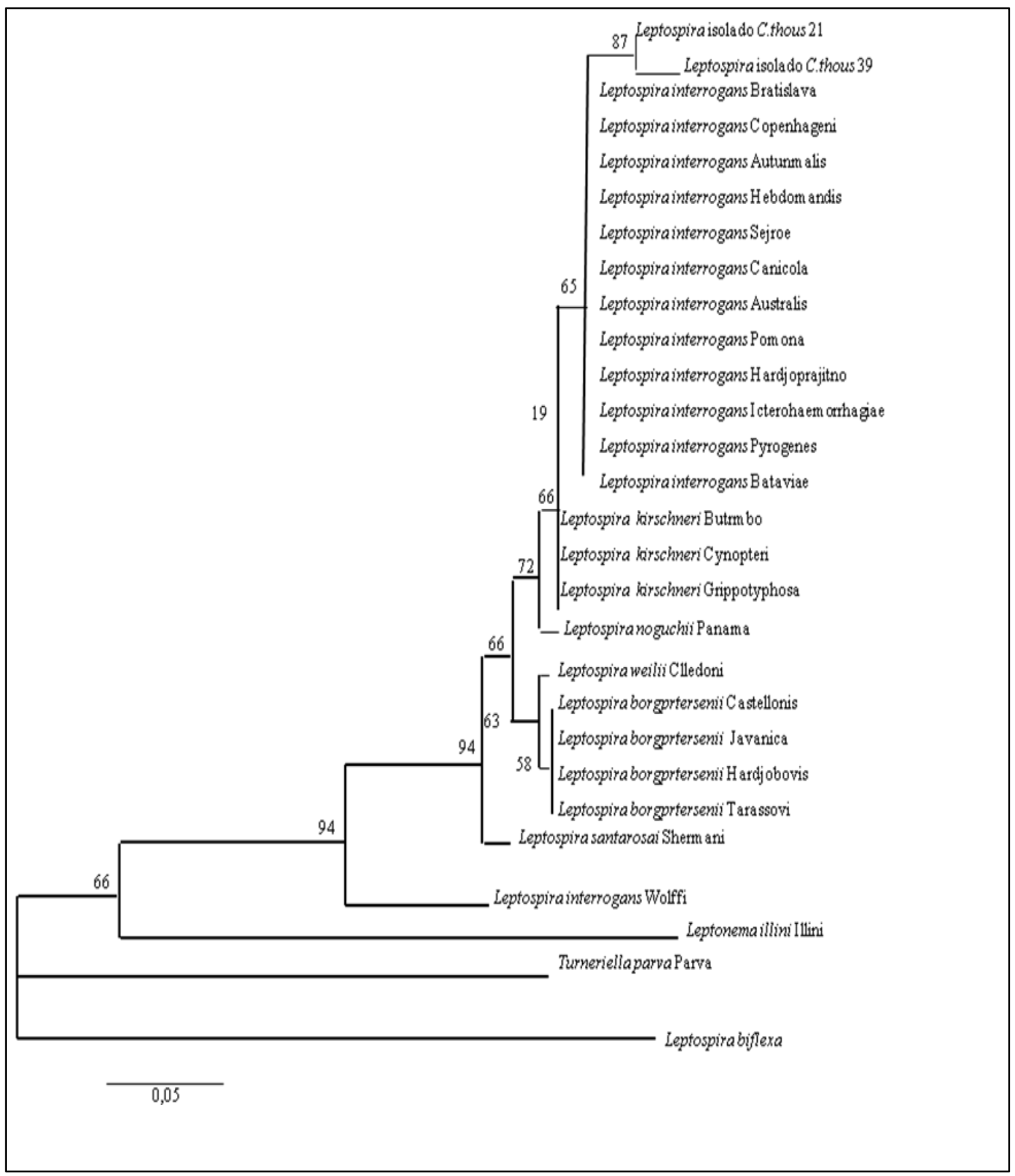

Figura 1 - Filogenia de Leptospira ssp. construída a partir do alinhamento de sequências parciais do gene 16S. O método utilizado foi o de Neighbour-Joining. O suporte de cada clado foi determinado por 1000 bootsprap indicando o valor dos nós internos (\%). 


\section{DISCUSSÃO}

Nasua nasua e C. thous apresentaram a maior frequência de reações positivas para Leptospira spp., tanto para os testes de SAM como de PCR. Ambas as espécies apresentam alta densidade nessa região e se distribuem por diversos ambientes no Pantanal (ALHO et al., 1987; TROLLE, 2003; BIANCHI, 2009; DESBIEZ \& BORGES, 2010). Como a transmissão ocorre por contato direto do agente, isso está diretamente relacionado à taxa de contato entre hospedeiro e/ ou à densidade desses no ambiente. Nesse contexto, tanto $N$. nasua quanto $C$. thous são potencialmente importantes na epidemiologia da leptospirose na área de estudo, uma vez que ambas as espécies são abundantes (ALHO et al., 1987; TROLLE, 2003; BIANCHI, 2009; DESBIEZ \& BORGES, 2010). Além disso, ambas as espécies visitam com frequência lagoas e campos inundáveis (ROCHA, 2006; BIANCHI, 2009).

Uma vez que o SAM representa um teste para identificar o sorovar predominante, o sorovar mais provável em C. thous foi o Hardjobovis (50\% de reações dominantes); enquanto para N. Nasua, Pomona foi o mais provável, com $38,46 \%$ de reações dominantes, sugerindo que $C$. thous e $N$. nasua são hospedeiros acidentais de tais sorovares podendo, além de desenvolver a doença, disseminar o agente nas áreas habitadas.

No levantamento realizado por JORGE et al. (2010), na região da reserva SESC Pantanal (Mato Grosso), 39,5\% (17/43) dos animais foram positivos para Leptospira spp. pela técnica de SAM, sendo o sorovar Autummalis o mais prevalente. SOUZAJUNIOR et al. (2002) encontrou $20 \%$ de $C$. thous e $12.9 \%$ de $N$. nasua reagentes para anticorpos de Leptospira spp no estado de Tocantins, corroborando os resultados do nosso estudo. O levantamento realizado no Tocantins detectou outros sorovares, como Fluminense e Javanica em $N$. nasua e Fluminense e Brasiliense em C. thous. No entanto, GIRIO et al. (2003) testou nove N. nasua na mesma região deste estudo, não encontrando nenhum dos animais reagentes para Leptospira spp.

Os roedores domésticos são os principais transmissores e reservatórios para leptospirose em humanos ou no meio urbano (BRASIL, 2009). Em $T$. Pachyurus, encontramos títulos equivalentes ao ponte de corte, o qual corresponde a uma reação positiva com título igual ou maior a 100. Com relação a isso, cumpre ressaltar que os roedores são os reservatórios mais adaptados à infecção por leptospiras e, por isso, podem não ter apresentado altos títulos no SAM, (BRASIL, 2009); entretanto, quando são observados os resultados da PCR, pode- se constatar que dois animais não reagentes na prova de SAM foram positivos na PCR, o que é bastante justificado, uma vez que a técnica de PCR, aplicada em amostras de sangue, detecta o agente em sua fase de bacteremia (SCARCELLI et al., 2003), enquanto a SAM detecta a presença de anticorpos, em fase posterior a essa (BRASIL, 2009). Dentre o sorovar mais provável está o Icterohaemorrhagiae, para o qual os roedores são considerados reservatórios (FAINE et al., 1999). Embora não existam trabalhos sobre Leptospira spp. infectando T. pachyurus, essa situação é bastante provável no Pantanal, uma vez que esse ecossistema reúne todas as condições ecológicas para manter a enfermidade de forma endêmica.

A não detecção de anticorpos ou DNA nas amostras coletadas dos roedores $O$. mamorae é provavelmente decorrente dos hábitos desta espécie, que é preferencialmente arborícola (BONVICINO et al., 2002) e sua frequência de captura em áreas alagadas é baixa (RADEMAKER et al., 2009). Assim, essa espécie estaria menos exposta à Leptospira spp, já que ambientes alagados são os mais favoráveis à transmissão do agente.

Os sorovares mais prováveis em carnívoros foram o Hardjobovis, Pomona e Icterohaemorrhagiae, porém este último apareceu somente em um indivíduo de $L$. pardalis. No entanto, baixos títulos sorológicos não devem ser considerados conclusivos para atribuir uma condição de não infectado ao animal, pois o ponto de corte do teste pode variar conforme espécie, o que significa que as frequências de animais expostos a um determinado parasita podem estar subestimadas (HERRERA et al., 2008).

Do espécime de C. thous identificado como $n^{\circ} 39$ foi anteriormente isolada uma amostra de Leptospira spp. (Delbem 2006, informe verbal) ainda não caracterizada. No presente trabalho, foram realizadas a sorologia e a PCR de amostras desse indivíduo e o sorovar mais provável foi o Hardjbovis (título de 1600), sendo também positiva frente à PCR. Pela análise parcial do gene $16 S$ comparada com sequências depositadas no GenBank, esse isolado possui maior identidade, $97 \%$ e-value $10^{69}$, com L. interrogans sorovar Sejroe cepa 3705 (número de acesso FJ154558.1). Os sorovares Hardjobovis e Sejroe pertencem ao mesmo sorogrupo (Sejroe).

O antígeno denominado "M-110/2006" utilizado na SAM foi produzido com um isolado obtido de um C. thous em pesquisa anterior. Quando as amostras de soro foram testadas para esse antígeno, $10 \%$ dos $C$. thous (1/10) e $23,07 \%$ dos $N$. nasua (3/13) foram reagentes, o que indica que esse antígeno está circulando no ambiente estudado, 
sugerindo que essas duas espécies estejam participando da sua cadeia de transmissão.

\section{CONCLUSÃO}

Podemos concluir que os sorovares mais prevalentes foram Hardjobovis, Pomona e Ictrerohaemorrhagiae, sendo que as espécies C.thous e N.nasua foram as que apresentaram maior reação positiva para Leptospira spp. E, quando o antígeno denominado "M-110/2006", foi isolado de C. thous, foi utilizado, essas duas espécies foram reagentes, indicando que $o$ antígeno está circulando no ambiente e sugerindo que elas estejam participando da sua cadeia de transmissão, devido à alta densidade e modo de vida desses animais. Com a técnica de sequenciamento foi possível verificar que esta amostra pertence ao mesmo sorogrupo do sorovar Hardjobovis.

Não houve diferença significativa entre as duas técnicas de diagnóstico utilizadas no trabalho, porém cada técnica pode ser utilizada em momentos diferentes da detecção do agente.

\section{REFERÊNCIAS}

ALHO, C.J.R.; LACHER, T.E.; CAMPOS, Z.M.S.; GONÇALVES, H.C. Mamíferos da Fazenda Nhumirim, sub-região de Nhecolândia, Pantanal do Mato Grosso do Sul: I - levantamento preliminar de espécies. Revista Brasileira Zoologia, v. 4, n. 2, p.151-164, 1987.

ARAUJO, F.R.; RAMOS, C.A.N.; LUIZ, H.L.; PEREZ, I.A.H.F.S.; OLIVEIRA, R.H.M.; SOUZA, I.L.F; RUSSI, L.S. Avaliação de um Protocolo de Extração de DNA Genômico a Partir de Sangue Total. Campo Grande: Embrapa GNPGC, Comunicado Técnico n. 120, 2009. 5p. Disponivel em:

http://www.infoteca.cnptia.embrapa.br/bitstream/doc/8533 64/1/COT120.pdf

AYRES, M.; AYRES, M. J.R.; AYRES, D.L.; SANTOS, A.A.S. BioEstat 5.0. Aplicações estatísticas nas áreas das ciências biológicas e médicas. Belém: Imprensa Oficial do Estado do Pará, 2005. 324p. Disponível em: > http://www.mamiraua.org.br/downloads/programas

BALL, A.E.; GRAVEKAMP, C.; HARTSKEERL, R.A.; DE MEZA-BREWSTER, J.; KOVER, H.; TERPSTRA, W.J.. Detection of Leptospires in urine by PCR for early diagnosis of leptospirosis. Journal of Clinical Microbiology, v. 32, n.8, p.1894-1898, 1994.

BARR, B.C.; ANDERSON, M. L. Infectious diseases causing bovine abortin and fetal loss. TheVeterinary Clinics of North America. Food Animal Practice, v.9, n.2, p.343-368, 1993.

BIANCHI, R.C. Ecologia de mesocarnívoros em uma área no Pantanal, Mato Grosso do Sul, 2009.193f. Tese
(Doutorado em Ecologia e Conservação) - Curso de Pósgraduação Universidade Federal do Mato Grosso do Sul, Campo Grande. Disponível em: http://www.cpap.embrapa.br/teses/online/TSE44.pdf acesso em: 2012-03-01.

BLAST N. Basic Local Alignment Search Tool - NCBI. Disponível em: http://blast.ncbi.nlm.nih.gov/

BONVICINO, C.R.; OLIVEIRA, J.A.; D'ANDREA, P.S. Guia dos roedores do Brasil, com chaves para gêneros baseados em caracteres externos. Rio de Janeiro: Centro Pan Americano de Febre Aftosa - OPAS/OMS. 2002. 120p. Disponível em: http://www.fiocruz.br/ioc/media/livro\%20roedores.p $\underline{\mathrm{df}}$

BRASIL. Ministério da Saúde. Secretaria de Vigilância em Saúde. Guia de Vigilância Epidemiológica. $7^{\circ}$ ed. Brasilia: Ministerio da Saúde. Seria A normas e manuais técnicos. 2009. 816p. Disponível em: http://portal.saude.gov.br/portal/arquivos/pdf/gve 7ed_we b_atual.pdf.

COLE, J.R; COLE, JR. J.R.; SULZER, C.R.; PURSELL, A.A. Improved microtechnique for the Leptospiral microscopic agglutination test. Applied Microbiology, v.25, n.26, p. 976-980. 1973.

DESBIEZ, A.L.J.; BORGES, P.A.L. Density, habitat selection and observations of South American coati Nasua nasua in the central region of the Brazilian Pantanal wetland. Small Carnivore Conservation, v. 42, p.14-18. 2010.

FAINE, S; ADLER, B; BOLIN, C; PEROLAT, P. Leptospire and Leptospirosis. Melborne: Medi Science, 1999. 272p.

FÁVERO, A.C.M.; PINHEIRO, S.R.; VASCONCELLOS, S.A.; MORAIS, Z.M.; FERREIRA, F.; FERREIRA NETO, J.S.. Sorovares de leptospiras predominante em exames sorologicos de bubalinos, ovinos, caprinos, equinos, suinos e cães de diversos estados brasileiros. Ciência Rural v. 32, n. 4, p. 613-619. 2002.

GALTON, M.M.; SULZER, C.R.; SANTA ROSA, C.A.; FIELDS, M.J. Application of a Microtechnique to the Agglutination Test for Leptospiral Antibodies. Applied Microbiology, v.13, n. 1, p. 81-85. 1965.

GANNON, W.L.; SIKES, R.S. The Animal Care and Use Committee of the American Society of Mammalogists. Guidelines of the American Society of Mammalogists for the use of wild mammals in research. Journal of Mammalogy, v.88, n.1, p.809-823. 2007.

GARCIA, E.A.; CASTRO, L.H.R. Analise da frequência de chuva no Pantanal Mato-Grossense. Pesquisa Agropecuaria Brasileira, v.21, n.9, p. 909-925. 1986.

GenBank Disponivel em: > http://www.ncbi.nlm.nih.gov

GIRIO, R.J.S.; PEREIRA, F.L.G.; FILHO, M.M.; MATHIAS, L.A.; HERREIRA, R.C.P.; ALESSI, A.C.; GIRIO, T.M.S. Pesquisa de anticorpos contra Leptospira 
spp. em animais silvestres em estado feral da região da Nhecolândia, Mato Grosso do Sul, Brasil. Utilização da técnica de imuno-histoquímica para a detecção do agente. Ciência Rural, v.34, n.1, p.165-169. 2003.

HERRERA, H.M.; LISBOA, C.V.; PINHO, A.P.; OLIFERES, N.; BIANCHI, R.C.; ROCHA, F.L.; MOURÃO, G.M.; JANSIN, A.M. The coati (Nasua nasua, Carnivora, Procyonidae) as a reservoir host for the main lineages of Trypanosoma cruzi in the Pantanal region, Brazil. Transactions Royal Society of Tropical Medicine and Hygiene, v.102, n11, p.1133-1139. 2008.

JORGE, R.S.P.; ROCHA.F.L.; JUNIOR, J.A.M.; MORATO, R.G. Ocorrência de patógenos em carnívoros selvagens brasileiros e suas implicações para conservação e saúde publica. Oecologia Australis, v.14, n3, p.686710. 2010.

LINZ, Z.C.; LOPEZ, M.L.; MAROJA, O.M. Instituto Evandro Chagas, 50 anos de contribuição a ciências biológicas e a medicina tropical In: Epidemiologia da Leptospirose com particular referência a Amazônia brasileira. Belém, 1986. p.733-764. Disponivel em: > http://iah.iec.pa.gov.br/iah/fulltext/pc/monografias/iec/iec 50anos/vol2/cap12(733-764).pdf.

MÉRIEN, F.P.; AMOURIAUX, P.; PERLOTA, P.; BARANTON, G.; SAINT GIRONS, I. Polymerase chain reaction for detection of Leptospira $\mathrm{spp}$ in clinical samples. Journal of Clinical Microbiology, n.30, v. 9, p. 2219-2224. 1992.

MOREY, R.E.; GALLOWAY, R.L.; BRAGG, S.L.; STEIGERWALT, A.G.; MAYER, L.W.; LEVETT, P.N. Species-specif identification of Leptospiraceae by $16 \mathrm{~S}$ rRNA gene sequencing. Journal of Clinical Microbiology, v. 44, n. 10, p. 3510-3516. 2006.

OIE. World organisation for animal health. Leptospirosis. Chapter 2.2.4. Disponível em: $<$ http://www.oie.int/eng/normes/mmanual/A 00043.htm $>$ Acesso em 22/01/2009. 2006.

RADEMARK, V.; HERRERA, H. M.; RAFELL, T. R.; D' ANDREA, P. S.; FREITAS, T. P. T.; ABREU, U. G. P. de; HUDSON, P. J.; JANSEN, A. M. What is the role of small rodents in the transmission cycle of Trypanosoma cruzi and Trypanosoma evansi (Kinetoplastida Trypanosomatidae)? A study case in the Brazilian Pantanal. Acta Tropica, v.111, n.2, p.102-107. 2009.
ROCHA, F.L. Área de uso e seleção de habitats de três espécies de carnívoros de médio porte na fazenda Nhumirin, e arredores, Pantanal da Nhecolândia, MS. 2006. 92f. Dissertação (Mestrado em Ecologia e Conservação) - Curso de Pós-graduação em Ecologia, Universidade Federal de Matogrosso do Sul, Campo Grande. Disponível em: > http://repositorio.cbc.ufms.br:8080/jspui/bitstream/123456 789/569/1/Fabiana\%20Lopes\%20Rocha.pdf. > Acessado em: 2012-03-01.

SAITOU, N.; NEI, M.The neighbor-joining method: a new method for reconstructing phylogenetic trees. Molecular Biology and Evolution, v.4, n.4, p. 406-425. 1987.

SCARCELLI, E.; PIATTI, R.M.; FEDULLO, J.D.L.; SIMON, F.; CARDOSO, M.V.; CASTRO, V.; MYASHIRO, S.; GENOVEZ, M.E. Leptospira spp. detection by polymerase chain reaction (PCR) in clinical sample of captitive Black-Capped Capution Monkey (Cebus apella). Brazilian Journal of Microbiology, v.34, n. 2, p.143-146. 2003

SOUZA-JUNIOR, M.F.; LOBATO, Z.I.P.; LOBATO, F.C.F.; MOREIRA, E.C.; OLIVEIRA, R.R.; LEITE, G.G.; FREITAS, T.D.; ASSIS, R.A. Presença de anticorpos da classe IgM de Leptospira interrogans em animais silvestres do Estado do Tocantins 2002. Revista da Sociedade Brasileira de Medicina Tropical, v.39, n.3, p. 292-294. 2006.

TAMURA, K.; DUDLEY, J.; NEI, M.; KUMAR, S. MEGA4: Molecular Evolutionary Genetics Analysis (MEGA) software version 4.0. Molecular Biology Evolution, v. 24, n.8, p.1596-1599. 2007.

TROLLE, M. Mammal survey in the southeastern Pantanal, Brazil. Biodiversity and Conservation, v.12, n.4, p. 823-836. 2003.

VIEIRA A.S.; ROSINHA,G.M.S., OLIVEIRA, C.E.; VASCONCELLOS, S.A.; LIMA-BORGES, P.A.; TOMÁS, W.M.; MOURÃO, G.M.;LACERDA, A.C.R.;SOARES, C.O.; ARAÚJO, F.R; PIOVEZAN, U.; ZUCCO, C.A.; PELLEGRIN, A.O. Survey of Leptospira spp in pampas deer (Ozotoceros bezoarticus) in the Pantanal wetlands of the state of Mato Grosso do Sul, Brazil by serology and polymerase chain reaction. Memórias Instituto Oswaldo Cruz, v.106, n.6, p.763768. 2011. 